Review

\title{
Biopesticides as Promising Alternatives to Chemical Pesticides: A Review of Their Current and Future Status
}

\author{
Lukmanul Hakim Samada and Usman Sumo Friend Tambunan \\ Bioinformatics and Biomedicals Research Group, Department of Chemistry, \\ Faculty of Mathematics and Natural Sciences, Universitas Indonesia, Depok, West Java, 16424, Indonesia
}

\author{
Article history \\ Received: 20-12-2019 \\ Revised: 23-03-2020 \\ Accepted: 14-04-2020 \\ Corresponding Author: \\ Usman Sumo Friend \\ Tambunan \\ Bioinformatics and \\ Biomedicals Research Group, \\ Department of Chemistry, \\ Faculty of Mathematics and \\ Natural Sciences, Universitas \\ Indonesia, Depok, West Java, \\ 16424, Indonesia \\ Email: usman@ui.ac.id
}

\begin{abstract}
Biopesticides are living organisms or natural products that control agricultural pests including bacteria, fungi, weeds, viruses and insects. Biopesticides can be classified into different categories, such as microbial pesticides, plant-incorporated protectants and biochemicals. Biopesticides are a crucial component of integrated pest management programs for pest control, which lead to more natural alternatives to chemical pesticides that are eco-friendly and safer. Since the emergence of biopesticides for potential pest management, numerous products have been released and some of them dominate the market. This review paper will discuss the current status, future prospect and challenges associated with the use of biopesticides in pest control.
\end{abstract}

Keywords: Biopesticides, Pests, Integrated Pest Management, EcoFriendly

\section{Introduction}

Agricultural pests, such as bacteria, weeds, insects and fungi can lower the yield and quality of crop production. The primary method used since the 1960s to control pests has been the intensive application of chemical pesticides (Kumar and Singh, 2015). Although pesticides have been successful at reducing pest populations, it is well known that their application can also have negative effects on the environment and the crops itself. Therefore, eco-friendly management is needed for sustainable crop production. Biopesticides can be applied as an alternative to the use of chemical pesticides as they have been shown to be effective for pest management and the generation of sustainable agricultural products (Prabha et al., 2016). However, technical obstacles and challenges have limited their effectiveness to date (Nielsen et al., 2008). In the European Union, the impact of Integrated Pest Management (IPM) policies provides the incentive for novel pest management strategies, especially the use of biopesticides, including living microorganisms or natural products (Chandler et al., 2011).

Several factors indicate that biopesticides are excellent alternatives to synthetic pesticides. Specifically, they are highly effective, target-specific and have fewer environmental risks. Biopesticides can come from a wide diversity of organisms and many products have been released and registered in the agromarket.
Biopesticides allow for a sustainable approach for improved crop production, which should increase their use and popularity in the coming years (Mishra et al., 2015). Moreover, opinions about biopesticide use have begun to change because of the recent recognition of the environmental consequences of chemical pesticides. Other factors contributing to their increased use are advances in activity spectra spots and improved options for delivery and application (Glare et al., 2012).

Current research into biopesticides focuses on the improvement of their action spectra, including mechanisms to replace the use of chemical pesticides in IPM plans (Nawaz et al., 2016). IPM is a method to incorporate chemical, biological and physical methods for pest control (Ghewande and Nandagopal, 1997). The main challenges of new biopesticides in the growth and utilization are how to market or promote it (Tripathi et al., 2020) and how to enhance the stability and residual action of biopesticide (Damalas and Koutroubas, 2018). Previously, there were several methods applied for handling pests, such as traditional methods, chemical methods and biological methods (Lindsey et al., 2020).

This review aims to summarize the current status of biopesticides in agriculture and research, their role in IPM plans through the combination of biological methods and other pest control methods and future strategies to improve their commercialization and global reach for effective pest control. 


\section{Types of Biopesticide and Advantages}

Biopesticide or biological pesticides can be defined as a natural product from living organisms including plants, nematodes, minerals and microorganisms, such as bacteria, fungi and viruses, that limit or reduces pest populations. Biopesticide has more specific pests target than a chemical pesticide, thus it can be reduced the risk of other organisms, such as mammals and birds (Thakore, 2006; Glare et al., 2012). The use of biopesticides continues to increase globally each year. The largest biopesticide market is in North America (44\%), with the European Union and Oceania each having a 20\% market share, Latin and South American countries at $10 \%$ and Asia and India at approximately 6\% each (Bailey et al., 2010). The Bacillus thuringiensis (Bt) as a sort of biological control that could eradicate lepidopterans have dominated the biocontrol market that demonstrated in 1990 reached $90 \%$ of the biocontrol sales (Berini et al., 2018).

Biopesticides can be classified into three primary categories. The first group is referred to as microbial pesticides, which include products that come from microorganisms such as bacteria, fungi, viruses, protozoa and algae. For example, fungi can control certain weeds and eradicate specific insects. In addition, Bacillus thuringiensis $(\mathrm{Bt})$ often is used to control insects on potato, cabbage and other crops. Microbial pesticides commonly control pests with their specific toxic metabolites, which lead to disease to pests and they can also inhibit the formation of other microorganisms. The second group includes pesticidal substances in plants that result from plant genetic modification. The prime example is the transgenic expression of the $\mathrm{Bt}$ gene that allows plants to intrinsically make a bacterial protein that kills pests. Finally, there are nontoxic biochemical pesticides that occur naturally to control pests, such as plant growth regulators that interrupt the growth, mating, or attractive pheromones in pests (Gupta and Dikshit, 2010; Kachhawa, 2017).

Most biopesticides work because of chemical reactions with the pests. For example, biopesticides from fungi are employed to control weeds, beneficial bacterial pesticides are used to control fungal and bacterial disease and viral pesticides are used to resist insect pests (Hubbard et al., 2014). The pest like fungi can infect the plants through their stomata or micropores in the leaf epidermis (Baarlen et al., 2007). A coherent plan is still required that ensures proper development of biopesticides and bio-inoculants to maximize their outcome, effectiveness, stability and delivery (Hynes and Boyetchko 2006). Moreover, active substances must account for the evolution of resistance that emerges during pesticide use. Biopesticides, such as spores of entomopathogenic fungi, have been shown to lead to substantial mortality of 7-14 days following exposure (Blanford et al., 2011).

\section{The Role of Biopesticides in Integrated Pest Management}

As pest problems continue to increase globally and agriculture is now a global enterprise, IPM programs seem as a critical means to control the spread of pests. In addition, pesticide resistance has become a big problem. To address these problems, biopesticides have become an integral part of the programs in the IPM and biointensive pest management. Biopesticides are ecofriendly and can be used in some organic farming practices to protect against enemies and reduce chemical insecticides (Shishir et al., 2015).

The excellent potential for new biopesticides is demonstrated by farmers that attempt to use other biopesticides or botanical products, even if they are not yet commercially available. Yet existing practices for controlling pests need to be summarized and farmers need greater education about the use of alternative pest control methods. The goal of the IPM system is to provide a means to control and reduce the incidence of resistance to chemical pesticides. IPM uses multiple natural and chemical approaches to control pests, which reduces dependency on chemical means. For example, in Thailand, biopesticides, such as neemand $\mathrm{Bt}$, have shown great potential as insecticides, when used in an IPM strategy, to control M. vitrata (Kumar et al., 2014). Several botanical products and experimental conventional chemicals indicate their potential to significantly improve tomato and bell pepper production under glasshouse conditions (George et al., 2015).

Invasive species, such as the Guatemala potato tuber moth Tecia solanivora (Povolny) (Lep. Gelechiidae) from Mesoamerica, have spread greatly in recent decades. This moth species is the primary potato pest in Venezuela, Colombia and Ecuador and there are no effective control methods being used by farmers. To overcome this problem, biopesticides have been expanded and used in an IPM program by following these three steps; (1) identify entomopathogenic viruses by extensive bioprospecting in 12 countries around the world, (2) 20 Phthorimaea operculella granulovirus (PhopGV) were characterized genetically and biologically so that the best candidate for biopesticide formulation could be selected and (3) biopesticide dust formulation was tested by mixing a dry carrier such as $\mathrm{CaCO}_{3}$ with distinct adjuvants $\left(\mathrm{MgCl}_{2}\right.$ or an optical brightener or soy lecithin) and distinct specific quantities of virus (JLZ9f) (Carpio et al., 2013). To protect the crop, more sustainably used alternative instruments are being evaluated and are providing relief. Natural products in biopesticides and biological control, 
including predatory insects are emphasized for use. The important thing for the success of IPM is to evaluate the integration of non-synthetic insecticides and biological control methods (Scudeler et al., 2017).

For example, Pseudomonas fluorescens (Pf-CL145A) is sold as a dreissenid or bivalvia (i.e., any member of the Dreissenidae). Dressenidae is a family of small freshwater mussels, aquatic bivalve molluscs) control agents used in IPM in infested water pipes to reduce the use of a more broad-spectrum chemical (Molloy et al., 2013). It has been suggested to use biopesticides in teak nurseries as a replacement of toxic pesticides to resist the white grub (Meshram and Homkar, 2011). In addition, there are four levels of integration of orchard IPM (Prokopy et al., 1994). The first level IPM integrates biologically and chemically based pest management strategies, for example, weeds, arthropods, diseases and vertebrates. The second level integrates multiple management strategies for all pest classes. The third level integrates approaches with the whole farm system of crop production. Finally, the fourth level integrates cultural, social and political realms by examining all concerns, from the farmer, product distributor, instructor, researcher, private consultant, industry, the farmer's neighbor, the environmentalist, to the regulatory agency.

In Brazil, the IPM of soybean has been one of the most successful programs of pest management in the world. It has reduced the amount of insecticide usage by $50 \%$ (Panizzi, 2013) by including natural products containing viruses, bacteria and fungi. As a consequence, IPM is becoming popular among farmers, policymakers and researchers. IPM focuses on cheap pesticides and more renewable technologies available to the resourcepoor farmer, including biological control and host plant resistance (Thomas, 1999). The use of biological control could lower greenhouse gases emission compared to chemical pesticides (Heimpel et al.., 2013). The core biopesticides used in IPM are microbial pesticides, especially $\mathrm{Bt}$ on several vegetables in California and Mexico. Improving $\mathrm{Bt}$ and the transgenic plants containing Bt genes will improve the efficacy, broader host range and increased residual activity. Because of the many obstacles to the IPM including lack of education and infrastructure, farmers might abandon the IPM strategy and use new biotechnological products. It is important that improved microbial agents and pestresistant plants are made familiar to the farmers as a choice that can be integrated into the pest management system as opposed to a panacea that will solve recurring pest problems (Marrone, 1994).

For fulfilling the special local needs, IPM technology should be regionally distributed. This should consider local differences and production practices, policy issues, economics and regulatory considerations. Execution of IPM depends on the efficient distribution of information in books, information bulletins, internet services and fact sheets. Demonstration plots and workshops for farmers are beneficial (Jackson et al., 2002). In the past 20 years, the growth of global pesticides has reached 3.5 billion $\mathrm{kg} /$ year, with a price of $\$ 45$ billion. External costs of pesticides are \$4-19 (€3-15) per kg of active ingredient applied. Through an IPM system, pesticide usage will be reduced. For example, data from 85 IPM projects from 24 countries throughout Asia and Africa carried out over the past 20 years (Pretty and Bharucha, 2015) show that IPM has increased the use of ecological farming methods, requiring fewer pesticides, which has resulted in reduced risks of resistance, human poisoning and pollution (Jørs et al., 2017).

To restrict the toxic chemical use in Bangladesh, where high population density and few natural resources exist, farmers should adopt IPM techniques. However, despite traditional prolongation programs, few of the 14.7 million farm households across the whole country are using these strategies. Providing IPM information and training to show the effectiveness and economic benefits of IPM would facilitate the broader implementation of IPM strategies (Harris et al., 2013). The concept of IPM is a powerful tool for sustainable agriculture, which has the potential to serve as a framework for developing research and implementation of numerous control approaches that can protect human health and environment (Edson et al., 2013). Currently, the investment of some agricultural companies leads to fungicides to actualize the more sustainable integrated pest management program in organic and conventional plants (Mascarin et al., 2018). Through the IPM program, biopesticides can substitute the harmful pesticides because of low risk and safer. The previous study has shown that IPM was cost-effective to control pests of cauliflower in late winter (Ahuja et al., 2015).

\section{Current Status of Biopesticides}

The implementation of biopesticides is still limited compared with synthetic chemical pesticides due to the expensive production methods, poor storage stability, susceptibility to environmental conditions, efficacy problems and others. Some of these problems can be solved by improvements in the formulation, which has been successful in increasing and sustaining biopesticide activity (Gasic and Tanovic, 2013). In addition, the other hurdles in commercialization are quality control problems, concise shelf-life, low awareness and higher expense (Arthurs and Dara, 2018).

Commercially, there are some biopesticides available to farmers. According to present information, there are about 175 registered biopesticides globally, with 700 active substance products available for use. In India, only 12 biopesticides have been registered including bacterial, two viral, three fungal and two plant products. 
Bt, Trichoderma viride, Metarrhizium, Beauveria bassiana, nuclear polyhedrosis virus and neem currently are used to protect plants (Rao et al., 2007). Bt is the primary biopesticide used and it has microbial, biochemical and plant-incorporated protectants variants. $\mathrm{Bt}$ has been used to control lepidopteran, dipteran and coleopteran insects for more than three decades. Presently, about $75 \%$ of biopesticide use consists of Btbased products. As an effective microbial pesticide, mostly biochemical biopesticides worldwide are the purified toxin from this strain. Plant-incorporated protectants are transgenic organisms expressing the gene coding for the Bt toxin. The biopesticide landscape has been dominated by this microorganism, yet additional strategies are necessary, as resistance against Bt-based products is beginning to evolve (Olson, 2015). Indeed, novel recombinant $\mathrm{Bt}$ strains with increased toxicity and broadened insecticidal spectrum have been developed (Kaur, 2000). Despite the challenges, increased Bt biopesticides use will continue, because of the expansion of organic markets and the demand for eco-friendly pest control alternatives in gardens (Saiyad, 2017).

Another naturally occurring chemical substance, Azadirachtin, is a tetranortriterpenoid isolated from neem that can interfere with insect metamorphosis. Azadirachtin and other limonoids are found in Azadirachta indica seeds, which can be used as biopesticides to protect the crop. Unfortunately, the availability of seeds is limited to dry zones, which has stimulated novel biotechnological production methods to increase supply (Prakash and Srivastava, 2008).

An excellent alternative to synthetic chemical insecticides to protect crops comes from vegetable oils (Rongai et al., 2008). Senecio species have been commonly used as medicines to cure injuries, as antiinflammatory agents, as an antiemetic and as dry powder or coarse extract to protect crops (Portero et al., 2012). The by-products acquired following mechanical extraction from the seeds are oilseed cakes. They can be differentiated into edible and nonedible types. Edible oil seed cakes have a high nutrition value and are used as animal feed. However, nonedible oil cakes from Azadirachta indica (neem), Jatropha curcas (jatropha), Madhuca indica (mahua) andPongamia pinnata (karanja) cannot be used as animal feed because they contain toxic substances. Nevertheless, the toxicity of nonedible oil cakes makes them effective biopesticides against termites (Sharma et al., 2013). In addition, Paenibacillus polymyxa can be utilized as a friendlier alternative to chemical fertilizer and multiple strains have been isolated that can be advantageous for antimicrobial, phosphate solubilization, nitrogen fixation, plant hormone production, or lignocellulose degradation (Weselowski et al., 2016).

Metabolites from the nematode symbiont Photorhabdus luminescens are a promising alternative to synthetic fungicides, as they have small environmental risk. They are effective against pecan scab because of the bioactive compound trans-cinnamic acid that acts as an antifungal (Bock et al., 2014). Beauveria bassiana is a pathogenic insect fungus that occurs in the soil, which can be used as a biopesticide in the management of crop pests. Fungal survival and infection potential are influenced by the soil $\mathrm{pH}$, the insect cuticle and its hemocoel (Padmavathi et al., 2003). Pathogen-based biopesticides also can be used to control pests. As an example, they are being used to treat a predominant apiculture pest, the ectoparasitic mite Varroa destructor. The first microbial control product registered in Japan in 1974 was Matsukemin, a cypovirus product, containing live and inactive Bt. Presently, there are 25 microbial insecticides on the market, with fewer than $2 \%$ of them in Japan. In China, the use of insect viruses as biological control agents began in the early 1960s and until now, more than 32 viruses in agriculture, pastures, forestry and domestic gardens have been used to control pests. In 2014, 57 products from 11 viruses have been approved by the Ministry of Agriculture of China, which amounts to 1600 tons of viral insecticidal formulations produced per year. This is approximately $0.2 \%$ of the total of insecticide production of China (Sun, 2015). In certain markets, this microbial biopesticide commercializes in limited amount to treat the arthropods (Lacey et al., 2015).

In several parts of the world, attention has shifted to the exploitation of higher plant products as chemotherapeutics. Botanical pesticides are now globally used. Pyrethroids and neem products are made as botanical pesticides and several essential oils from higher plants are used as antimicrobials (Dubey et al., 2008). Fungi also are important biological control agents against pathogens (Rostami et al., 2017). Many biological methods have been recognized. For instance, when the viruses attack the plants through the wounds or by cutting the plant's parts because of pests or humans. As for the way to stop the entry of viruses is to develop the genetically engineered species that is resistant to the virus and perform certain cultures (Williamset al., 2017).

A few biopesticides are ideal substitutes for conventional synthetic chemical pesticides, yet some of them show certain toxicity that should be a concern for researchers in the field (Leng, 2011). Continued development and commercialization of biopesticides will require a concrete structural strategy. Although genetic engineering has emerged as a new dimension in the management of pests, there are potential ecological, socioeconomic and ethical issues associated with their use. IPM has been developed for various agricultural crops. However, its wide application has not been achieved. Therefore, strategies need to be developed to select appropriate agents to control pests, to investigate 
the product readiness on a large scale and to maintain quality control (Jindal et al., 2013). Below, we summarize the major biopesticides currently in use in India (Alam, 2000).

\section{Bacillus thuringiensis}

As the most commonly utilized biopesticide in the world, this pesticide acts as a pathogen to some of the most destructive lepidopteran pests, including stem borers on rice and American bollworm on cotton. When the pest larvae ingest $\mathrm{Bt}$, toxins that released destroy the midgut of the pests. Three companies in India market Btbased pesticides. In 1999, the total sale was approximately 70 tons.

\section{Baculoviruses}

These are viruses that act specifically against targets by infecting and damaging various crucial plant pests. Baculoviruses are limited to tackle lepidopteran pests of vegetables, rice and cotton. To produce them at a large scale has been challenging and thus, their use is limited to small areas. In India, they are not available commercially, but IPM centers and state agricultural departments have produced them on a small scale.

Neem

Originating from the neem tree (Azadirachta indica), chemicals, such as azadirachtin, influence the digestive and reproductive process of some important pests. An effective formulation has been commercialized. Demands have increased, because neem is non-toxic to mammals and birds and it is noncarcinogenic. Nevertheless, the current demand is extremely small. In India, there are more than 100 companies registered to produce neem-based pesticides, but actually, a few of them make it.

\section{Trichoderma}

This is an effective fungicide that resists soil-borne fungi, such as root rot. It is especially relevant for dryland crops, such as green gram, groundnut, black gram and chickpea, which are susceptible to these diseases. In India, three firms produce Trichoderma.

\section{Trichogramma}

These are small wasps that act exclusively as eggparasites. They lay eggs in the eggs of various lepidopteran pests. After hatching, Trichogramma larvae consume and damage the host egg. Trichogramma is effective at resisting lepidopteran pests, such as pink bollworm, sugarcane internode borer, sooted bollworms in cotton and stem borers in rice. In addition, they combat pests of fruit and vegetable crops. Trichogramma is a biocontrol agent that is famous in India, particularly because it destroys pests in the egg phase. This makes sure that the parasite is damaged before any damage is done to the plant crop. Several countries produce Trichogramma on a large scale.

\section{Future Prospect of Biopesticides}

Farmers need safer pesticides to protect their plant crops, making biopesticides an excellent option rather than chemical agents. Yet implementation, manufacturing and development of biopesticides continue to have many challenges. To support the commercialization of biopesticides, additional research in production, delivery and formulation must be conducted. Public-private sector integrations have the potential to improve the manufacturing, development and sale of environmentally friendly alternatives to chemical pesticides in developing countries. In addition, additional support of public-funded programs, commercial investors and pesticide firms is needed as well. An important issue is developing strict regulatory mechanisms to keep biopesticides available at affordable prices in developing countries. Thus, several obstacles remain for the development of several biopesticides (Kumar and Singh, 2015).

The "first generation" of transgenic plants containing $B t$ genes will be followed by more sophisticated "second" and "third" generation plants with greater flexibility in IPM. These include plants with inducible and tissue-specific expression systems and multiple engineered genes. The combination of genetically engineered and modified $B t$ microbial products, traditional $B t$ and novel engineered plant products will greatly improve future IPM programs (Prior, 1996). Since the early 1980s, scientific activity in mycoherbicide research also has enhanced rapidly, in terms of the number of both weeds controlled and candidate pathogens studied. There has been a global increase in unregistered and registered mycoherbicides. Similarly, there has been an increase in the quantity of United States patents issued for mycoherbicidal technology (El-Sayed, 2005).

New interests in biopesticides that combine health/environmental issues and commercial pressures for agrochemicals have caused significant advances in research of biological control agents. By the available technology, the reliability and efficacy of biopesticides can be improved. In addition, product costs are continuing to decline due to developments in production technology. There are still a lot of challenges that need to be addressed, yet numerous market projections reflect the potential for commercial biopesticide production. $\mathrm{Bt}$ production particularly is expected to continue to grow, but significant sales in bio-fungicides and bioherbicides are expected as well (Rodgers, 1993).

It is very important to develop IPM programs that fully favor the use of biopesticides. Conventional 
pesticides should be used minimally to reduce the evolution of pest resistance, which supports the widespread use of biopesticides and other environmentally friendly technologies. The way to correct pest management methods to lower pesticide use is exhibited by the present published activity concerning IPM programs. Thus, to reduce losses in crop yields, solutions should be established so that the pesticides' use also can be reduced. Strategies for protecting plants from the pests also should be developed to avoid the risks to human health and the environment (Villaverde et al., 2016). The efficacy can be enhanced through some strategies such as enhanced production, formulation and advanced technology. In addition, the increased number of laboratories and firms that develop liquid culture methods and in vivo systems lead to the efficiency of production and lower expenses (Shapiro-Ilan et al., 2014).

In the future, environmental control strategies of insects based on the $\mathrm{Bt}$ and its insecticidal crystal proteins will continue to be improved, particularly as transgenic crops become adopted more widely. New toxin discovery and new recombinant DNA methods and proteomics approaches are being developed to change the way the toxin is presented to the target insects. As is known in numerous cropping systems all over the world, numerous natural baculoviruses have been utilized as pesticides. Soybean fields above two million hectares can be protected from velvet bean caterpillar by using baculoviruses, which has proven feasible and relatively cost-effective. Thus, efforts to increase the usage and production of baculovirus pesticides will likely follow two approaches (Szewczyk et al., 2006).

In the first approach,we assume that genetically unmodified natural baculovirus will be used as biological pesticides in several countries. Infection diagnostics, in vitro culture development and changes in biopesticide formulations suggest future improvements in biopesticides application. Better diagnostics permit for faster virus detection and prediction of spread. Contamination with other microorganisms in the field is prevented by in vitro culturing methods and biopesticide costs; continue to decline. Meanwhile, stability can be increased through improved formulations.

In the second approach, countries will incorporate genetically modified organisms. The primary goal of this approach is to accelerate the pesticidal activity of baculoviruses that normally have long lag times in their activity. Thus, modifications of the baculovirus genome genetically with genes of another pathogen potentially can improve reaction times.

In agricultural pest management in organic farming, botanical pesticides are appropriate to use. In developing countries, botanical pesticides have an important role in the production and protection of food. Modern society tends "green consumerism" that has led to reductions in synthetic substances in food in favor of plant-based products. They are safe options for eco-friendly plant pest management (Dubey et al., 2010). A significant role will be exhibited by natural product chemicals in the future to control plant pests in industrialized countries or developing countries (Dimetry, 2012). Moreover, because soil organic substances are enhanced through organic farming, organic agriculture may assist in improving and conserving valuable resources, including topsoil, nutrient loss, compaction and erosion. Trees, leguminous plants and shrubs are being used by organic farmers to stabilize the soil. To supply nutrients, compost and dung are being used and to conserve groundwater and to prevent erosion, terracing is being used (Umar, 2013). Perhaps it is time to refocus research attention on developing and applying recognized botanicals rather than refining more plants (Cavoski et al., 2012).

To encourage research and usage of neem products, further exploration and exploitation of biotechnology and biopharmaceutical options will be necessary. Commercial neem formulations must be produced and manufactured. Crude formulations typically are used because it degrades quickly. There need to be fewer requirements for the labor of certified commercial neem pesticides and longer-term stability of these pesticides can be achieved under ultraviolet rays. There are two suggestions to increase the use of neem for protecting the crops: (1) To enhance neem bioefficacy, which gives it a broader spectrum and checks the risk for developing resistance; and (2) preparation of several botanical pesticides should include a synergist, such as piperonyl butoxide, to enhance pesticide effectiveness (Dar et al., 2014).

An important part of management programs remains the protection of grains and choices for storing them. Without grain protectants, serious economic consequences would ensue, particularly in industries with narrow profit margins. A promising change in management will be from chemical-based pest management to IPM using computer-based decision support systems (Arthur, 1996). Future considerations of bio-larvicide are increasing due to the activity, low costs and capability of protein toxins to endure in the anopheline larvae feeding zone. Solutions for controlling surface feeding Anopheles species sustainability and effectively include the development of toxins that are controlled release and surface-floating encapsulated in a living organism or with high-level expression. Nevertheless, the extrication of transgenic insecticidal organisms as larval food into the breeding habitat requires thorough monitoring (Mittal, 2003).

Biological control will not be successful on its own. Biological control should be integrated with other pest control techniques in integrated management programs. To enhance awareness of these options, promoting 
sustainable management procedures for pests and vectors needs international collaboration. Training that will be required to make appropriate decisions. Discussions to promote biological control by farmers and addressing concerns will be necessary (Greathead, 1991). For example, as demands in Canada for reduced pesticide use increased, the government created new regulations and management practices. Research has identified new biopesticides and teams have accelerated their expansion. These factors together have spurred a biopesticide revolution in Canada. Other countries all over the world, including Europe, also are enacting similar changes in their political and public views toward biopesticides and investment in research. The difference is Canada has capitalized on discovering the solution to pesticides decrease and has approved biopesticides as a strategy of reliable and peaceful replacement. Canada thus provides a nice example for other countries to follow in the future (Bailey et al., 2010).

Production of more biochemical biopesticides and core molecule sources for conventional products depends on knowledge of natural products chemistry. The future changes in the regulation of biopesticides will be influenced by biotechnology because approaches are changing rapidly to integrating microbial and biochemical agents in biopesticide activities via transgenic platforms. To facilitate registration of biopesticides, greater cooperation between governmental agencies will be needed. In several cases, present regulations are gradually eliminated because of better comprehension of the exposures and risks (Braverman et al., 2010).

Attention should be paid to the use of P. lilacinus and $P$. fluorescens in India for the management of nematodes, as it has not led to safer nematicides. Thus, further research is required as nematodes affect many of the primary crops (David, 2008). In addition, in the future, new approaches need to be explored to develop arthropod pesticidal agents that are more specific to insect biochemical sites but do not affect mammals. In IPM programs, developing efficient and safer pesticidal agents are the most important components (Damodaran and Elayidam, 2008). The eco-friendly nature of insecticides recently is the most important consideration. Therefore, in the future phytochemicals will become excellent alternatives to synthetic chemical insecticides because of their lower cost, safety and widespread availability (Pavela 2009; Pavela, 2007).

\section{Commercialization of Biopesticides}

Gardens, households, greenhouses, parks and organic agriculture are primary markets for biopesticides from plants. High demand for natural insecticides also exists in organic farming. Consumer demand for improved food safety and reduced environmental issues are the primary influence for expanding this market. In gardens and parks, natural pest control methods lead to the low persistence of environmental contamination, which reduces exposure to the toxic compounds. New biopesticides are required to fill this growing market. Agricultural waste products, easily available plants and traditionally used plants represent different potential sources to be considered. The steps to take to commercialize a new biopesticide include screening, followed by isolation, identification and assay for active compounds in the extracts (Pavela, 2007).

The sale of biopesticides has continued to grow by approximately $10 \%$ per year over the last decade. In 2014 , biopesticide use increased by $15.6 \%$. In 2009 , biopesticides accounted for $3.5 \%$ (the US $\$ 1.6$ billion) of the global pesticide market (Moosavi and Zare, 2015). For the last 30 years, numerous scientists and some commercial firms around the world have focused their research on postharvest biological control agents as alternatives to synthetic chemicals. In the laboratory, semi-commercial and commercial settings, testing and identification of some postharvest pathogens have generated new commercial products. However, the realization of their full commercial potential has yet to be achieved (Drobyet al., 2016).

The commercialization of biopesticides has several challenges (Chandler et al., 2011). For example, product commercialization of useful microbes will require the discovery and development of novel microbial strains, as well as the ability to scale up microbial cell production and product formulation. In addition, microbial performance tests in the field scale and standardization remain challenges that need to be addressed. The commercialization of microbial formulation products is expected to improve productivity and maintenance of the environment. The prospect of commercialization of microbes and microbial products in agriculture is extensive (Prihastuti, 2014).

Biocontrol of plant disease is relatively new compared with biocontrol of insect pests. The first bacterium registered by the United States Environmental Protection Agency (EPA) for grown gall control in 1979 was Agrobacterium radiobacter strain K84. The first fungus, Richoderma harzianum ATCC 20476, was registered with the EPA for plant disease control 10 years later. For plant disease control, there are a total of 14 bacteria and 12 fungi that have been registered with the EPA for plant disease control. Many of these products are presently sold commercially. Within the past 10 years, $65 \%$ of the EPA-registered organisms have been registered, with $36 \%$ being registered over the past 5 years (Fravel, 2005). Due to strict safety restrictions for chemical pesticides, biopesticide firms have an opportunity to establish safer alternatives.

The example of biopesticides commercialization is viral-based pesticides such as Baculoviruses, which now become potential biopesticides in the horticultural 
market. Nevertheless, the in vivo production should be carried out, which may confine profit and confine their use in the large farm (Grzywacz, 2016), the advanced capacity and technology can minimize the production costs such as when integrated with the conventional program which is known as Integrated Pest Management program (van Lenteren et al., 2017).

\section{Conclusion}

Biopesticides play an important role in IPM by reducing the use of synthetic chemical pesticides that are harmful to human and environmental health. Some biopesticides dominate the global market, including $B t$, neem, Baculoviruses and Trichoderma (fungicide). The demand for products that do not cause environmental damage and can maintain crop yields make biopesticides promising alternatives to traditional approaches. Regarding the resistance of pests, it is important to use suitable methods for pest control to increase agricultural yields. It is better to focus on using and developing either biological method or integrated biologicaltraditional method for pest extermination. Biopesticides are becoming more widely used because of improved application methods, eco-friendly and cheaper options for many formulations. Therefore, biopesticides are a more rational choice for pest management, especially as an improved balance between cost and efficiency becomes a reality in the near future.

\section{Acknowledgment}

We are grateful to the Directorate of Research and Community Engagement (DRPM), Universitas Indonesia for the support. The authors also would like to thank Enago (www.enago.com) for the English language review.

\section{Author's Contributions}

All authors equally contributed in this work.

\section{Ethics}

No potential conflicts of interest are declared.

\section{References}

Ahuja, D.B., U.R. Ahuja, S.K. Singh and N. Singh, 2015. Comparison of Integrated Pest Management approaches and conventional (non-IPM) practices in late-winter-season cauliflower in Northern India. Crop Protect., 78: 232-238.

DOI: 10.1016/j.cropro.2015.08.007

Alam, G., 2000. A study of biopesticides and biofertilisers in Haryana, India. Gate Keeper Series, 93: $1-25$.
Arthurs, S. and S.K. Dara, 2018. Microbial biopesticides for invertebrate pests and their markets in the United States. J. Invertebrate Pathol., 165: 13-21. DOI: $10.1016 /$ j.jip.2018.01.008

Arthur, H., 1996. Grain protectants: Current status and prospects for the future. J. Stored Prod. Res., 32: 293-302. DOI: 10.1016/S0022-474X(96)00033-1

Baarlen, P.V., A.V. Belkum, R.C. Summerbell, P.W. Crous and B.P.H.J. Thomma, 2007. Molecular mechanisms of pathogenecity: How do pathogenic microorganisms develop cross-kingdom host jumps? FEMS Microbiol. Rev., 31: 239-277. DOI: $10.1111 /$ j.1574-6976.2007.00065.x

Bailey, K.L., S.M. Boyetchko and T. Längle, 2010. Social and economic drivers shaping the future of biological control: A Canadian perspective on the factors affecting the development and use of microbial biopesticides. Biol. Control, 52: 221-229. DOI: 10.1016/j.biocontrol.2009.05.003

Berini, F., C. Katz, N. Gruzdev, M. Casartelli and G. Tettamanti et al., 2018. Microbial and viral chitinases: Attractive biopesticides for integrated pest management. Biotechnol. Adv., 36: 818-838. DOI: 10.1016/j.biotechadv.2018.01.002

Blanford, S., W. Shi, R. Christian, J.H. Marden and L.L. Koekemoer et al., 2011. Lethal and prelethal effects of a fungal biopesticide contribute to substantial and rapid control of malaria vectors. PLoS ONE, 6: 1-12. DOI: $10.1371 /$ journal.pone.0023591

Bock, C.H., D.I. Shapiro-Ilan, D.E. Wedge and C.L. Cantrell, 2014. Identification of the antifungal compound, trans-cinnamic acid, produced by Photorhabdus luminescens, a potential biopesticide against pecan scab. J. Pest Sci., 87: 155-162. DOI: $10.1007 / \mathrm{s} 10340-013-0519-5$

Braverman, M.P., J.J. Baron and D.L. Kunkel, 2010. An overview and future trends of US biopesticide regulations. Outlooks Pest Manage., 21: 132-134. DOI: $10.1564 / 21$ jun06

Carpio, C., O. Dangles, S. Dupas, X. Léry andM. López-Ferber et al., 2013. Development of a viral biopesticide for the control of the Guatemala potato tuber moth Tecia solanivora. J. Invertebrate Pathol., 112: 184-191. DOI: $10.1016 /$ j.jip.2012.11.014

Cavoski, I., P. Caboni and T. Miano, 2012. Natural pesticides and future perspectives. Pesticides Modern World, 1: 170-190. DOI: 10.5772/17550

Chandler, D., A.S. Bailey, G.M. Tatchell, G. Davidson and J. Greaves et al., 2011. The development, regulation and use of biopesticides for integrated pest management. Philosophical Trans. Royal Society B: Biol. Sci., 366: 1987-1998.

DOI: $10.1098 /$ rstb.2010.0390 
Damalas, C.A. and S.D. Koutroubas, 2018. Current status and recent developments in biopesticide use. Agriculture, 8: 1-6.

DOI: 10.3390/agriculture8010013

Damodaran, M. and U.G. Elayidam, 2008. Prospects and promises of endocrine biopesticides. J. Biopesticides, 1: 06-11.

Dar, S.A., N.A. Dar, M.A. Bhat and M.H. Bhat, 2014. Prospects, utilization and challenges of botanical pesticides in sustainable agriculture. Int. J. Molecular Biol. Biochem., 2: 1-14.

David, B.V., 2008. Biotechnological approaches in IPM and their impacts on environment. J. Biopesticides, 1: $1-5$.

Dimetry, N.Z., 2012. Prospects of botanical pesticides for the future in Integrated Pest Management programme (IPM) with special reference to neem uses in Egypt. Archives Phytopathol. Plant Protect., 45: 1138-1161.

DOI: $10.1080 / 03235408.2012 .657932$

Droby, S., M. Wisniewski, N. Teixidó, D. Spadaro and M.H. Jijakli, 2016. The science, development, and commercialization of postharvest biocontrol products. Postharvest Biol. Technol., 122: 22-29. DOI: 10.1016/j.postharvbio.2016.04.006

Dubey, N.K., R. Shukla, A. Kumar, P. Singh and B. Prakash, 2010. Prospects of botanical pesticides in sustainable agriculture. Curr. Sci., 98: 479-480.

Dubey, N.K., B. Srivastava and A. Kumar, 2008. Current status of plant products as botanical pesticides in storage pest management. Biopesticides, 1: 182-186.

Edson, M.Y.J., G.N. Ntsefong and A. Zachée, 2013. Development of integrated pest management system in agricultural production in Cameroon and the central African sub region. World J. Agric. Res., 1: 133-142. DOI: 10.12691/wjar-1-6-8

El-Sayed, W., 2005. Biological control of weeds with pathogens: Current status and future trends. J. Plant Dis. Protect., 112: 209-221.

Fravel, D.R., 2005. Commercialization and Implementation of Biocontrol. Annu. Rev. Phytopathol., 43: 337-359. DOI: 10.1146/annurev.phyto.43.032904.092924

Gasic, S. and B. Tanovic, 2013. Role of biopesticides in crop protection: Present status and future prospect. Pesticidi i Fitomedicina, 28: 97-102.

DOI: $10.2298 /$ PIF1302097G

George, D.R., J.A. Banfield-Zanin, R. Collier, J. Cross and A.N.E Birch et al., 2015. Identification of novel pesticides for use against glasshouse invertebrate pests in UK tomatoes and peppers. Insects, 6: 464-477. DOI: 10.3390/insects6020464

Ghewande, M.P. and V. Nandagopal, 1997. Integrated pest management in groundnut (Arachis hypogaea L.) in India. Integr. Pest Manag. Rev., 2: 1-15. DOI: $10.1023 / \mathrm{a}: 1018488326980$
Glare, T., J. Caradus, W. Gelernter, T Jackson and N. Keyhani et al., 2012. Have biopesticides come of age? Trends Biotechnol., 30: 250-258.

DOI: 10.1016/j.tibtech.2012.01.003

Greathead, D.J., 1991. Biological control in the tropic: Present opportunities and future prospects. Insect Sci. Applic., 12: 3-8. DOI: $10.1017 / \mathrm{S} 1742758400020464$

Grzywacz, D., 2016. Basic and applied Research: Baculovirus. In: Microbial Control of Insect and Mite Pests: From Theory to Practice, Lacey, L.A. (Ed.), Academic, Amsterdam,

ISBN-13: 978-0-12-803527-6, pp: 27-46.

Gupta, S. and A.K. Dikshit, 2010. Biopesticides: An ecofriendly approach for pest control. J. Biopesticides, 3: 186-188.

Harris, L.M., G.W. Norton, A.N.M.R. Karim, J. Alwang and D.B. Taylor, 2013. Bridging the information gap with cost-effective dissemination strategies: The case of integrated pest management in Bangladesh. J. Agric. Applied Econom., 45: 639-654.

DOI: $10.1017 / \mathrm{S} 1074070800005174$

Heimpel, G.E., Y. Yang, J.D. Hill and D.W. Ragsdale, 2013 Environmental consequences of invasive species: greenhouse gas emissions of insecticide use and the role of biological control in reducing emissions. PLoS ONE, 8: e72293-e72293.

DOI: 10.1371/journal.pone.0072293

Hubbard, M., R.K. Hynes, M. Erlandson and K.L. Bailey, 2014. The biochemistry behind biopesticide efficacy. Sustainable Chem. Processes, 2: 1-8. DOI: 10.1186/s40508-014-0018-X

Hynes, R.K. and S.M. Boyetchko, 2006. Research initiatives in the art and science of biopesticide formulations. Soil Biol. Biochem., 38: 845-849. DOI: 10.1016/j.soilbio.2005.07.003

Jackson, D.M., J.R. Bohac, K.M. Dalip, J. Lawrence and D. Clarke-Harris et al., 2002. Integrated pest management of sweet potato in the caribbean. Acta Horticulturae, 583: 143-154.

Jindal, V., G.S. Dhaliwal and O. Koul, 2013. Pest management in 21st century. Roadmap Future, 9: 1-22.

Jørs, E., A. Aramayo, O. Huici, F. Konradsen and G. Gulis, 2017. Obstacles and opportunities for diffusion of integrated pest management strategies reported by Bolivian small-scale farmers and agronomists. Environ. Health Insights, 11: 1-14. DOI: $10.1177 / 1178630217703390$

Kachhawa, D., 2017. Microorganisms as a biopesticides. J. Entomolgy Zool. Stud., 5: 468-473.

Kaur, S., 2000. Molecular approaches towards development of novel Bacillus thuringiensis biopesticides. World J. Microbiol. Biotechnol., 16: 781-793. DOI: 10.1023/A:1008931207374 
Kumar, P., L.Y.Z. Huang and R. Srinivasan, 2014. Effect of three commercial biopesticides of neem (Azadirachta indica) and Bacillus thuringiensis on legume pod borer (Maruca vitrata) (Lepidoptera: Crambidae) in Thailand. Int. J. Tropical Insect Sci., 34: 80-87. DOI: 10.1017/S1742758414000265

Kumar, S. and A. Singh, 2015. Biopesticides: Present status and the future prospects. J. Fertilizers Pesticides, 6: 1-2. DOI: $10.4172 / 2471-2728.1000 \mathrm{e} 129$

Lacey, L.A., D. Grzywacz, D.I. Shapiro-Ilan, R. Frutos and M. Brownbridge et al., 2015. Insect pathogens as biological control agents: Back to the future. J. Invertebrate Pathol., 132: 1-41. DOI: 10.1016/j.jip.2015.07.009

Leng, P., 2011. Applications and development trends in biopesticides. African J. Biotechnol., 10: 19864-19873. DOI: 10.5897/AJBX11.009

Lindsey, A.P.J., S. Murugan and R.E. Renitta, 2020. Biocatalysis and agricultural biotechnology microbial disease management in agriculture: Current status and future prospects. Biocatalysis Agric. Biotechnol., 23: 1-12.

DOI: $10.1016 /$ j.bcab.2019.101468

Marrone, P.G., 1994. Present and future use of Bacillus thuringiensis in integrated pest management systems: An industrial perspective. Biocontrol Sci. Technol., 4: 517-526. DOI: $10.1080 / 09583159409355365$

Mascarin, G.M., R.B. Lopes, I.D. Jr, E.K.K. Fernandes and C. Luz et al., 2018. Current status and perspectives of fungal entomopathogens used for microbial control of arthropod pests in Brazil. J. Invertebrate Pathol., 165: 46-53.

DOI: 10.1016/j.jip.2018.01.001

Meshram, P.B. and U. Homkar, 2011. Effects of sowing date and biopesticide on density of white grub Holotrichia serrata in a teak nursery. J. Tropical Forest Sci., 23: 358-362.

Mishra, J., S. Tewari, S. Singh and N.K. Arora, 2015. Biopesticides: Where we stand. Plant Microbes Symbiosis: Applied Facets, 9: 37-75.

DOI: $10.1007 / 978-81-322-2068-8$

Mittal, P.K., 2003. Biolarvicides in vector control: Challenges and prospects. J. Vector Borne Dis., 40: 20-32. PMID: 15119068

Molloy, D.P., D.A. Mayer, M.J. Gaylo, J.T. Morse and K.T. Presti et al., 2013. Pseudomonas fluorescens strain CL145A - a biopesticide for the control of zebra and quagga mussels (Bivalvia: Dreissenidae). J. Invertebrate Pathol., 113: 104-114.

DOI: 10.1016/j.jip.2012.12.012

Moosavi, M.R. and R. Zare, 2015. Factors affecting commercial success of biocontrol agents of phytonematodes. Biocontrol Agents Phytonematodes, 1: 423-445.
Nawaz, M., J.I. Mabubu and H. Hua, 2016. Current status and advancement of biopesticides: Microbial and botanical pesticides. J. Entomol. Zool. Stud., 4: 241-246.

Nielsen, A.L., K.O. Spence and E.E. Lewis, 2008. Efficacy patterns of biopesticides used in potting media. Biopesticide Int., 4: 87-101.

Olson, S., 2015. An analysis of the biopesticide market now and where it is going. Outlooks Pest Manage., 26: 203-206. DOI: $10.1564 / \mathrm{v} 26$ oct_04

Padmavathi, J., K.U. Devi and C.U.M. Rao, 2003. The optimum and tolerance $\mathrm{pH}$ range is correlated to colonial morphology in isolates of the entomopathogenic fungus Beauveria bassiana - A potential biopesticide. World J. Microbiol. Biotechnol., 19: 469-477. DOI: 10.1023/A:1025151000398

Panizzi, A.R., 2013. History and contemporary perspectives of the integrated pest management of soybean in Brazil. Neotropical Entomol., 42: 119-127. DOI: $10.1007 / \mathrm{s} 13744-013-0111-y$

Pavela, R., 2009. Larvicidal effects of some Euro-Asiatic plants against Culex quinquefasciatus Say (Diptera: Culicidae). Parasitol. Res., 105: 887-892. DOI: $10.1007 / \mathrm{s} 00436-009-1511-0$

Pavela, R., 2007. Possibilities of botanical insecticide exploitation in plant protection.Pest Technol., 1: 47-52.

Portero, A.G., A. González-Coloma, M. Reina and C.E. Díaz, 2012. Plant-defensive sesquiterpenoids from Senecio species with biopesticide potential. Phytochem. Rev., 11: 391-403. DOI: $10.1007 / \mathrm{s} 11101-013-9279-3$

Prabha, S., Yadav, Ashwani, A. Kumar and Yadav et al., 2016. Biopesticides - an alternative and eco-friendly source for the control of pests in agricultural crops. Plant Archives, 16: 902-906.

Prakash, G. and A.K. Srivastava, 2008. Production of biopesticides in an in situ Cell retention bioreactor. Applied Biochem. Biotechnol., 151: 307-318. DOI: $10.1007 / \mathrm{s} 12010-008-8191-6$

Pretty, J. and Z.P. Bharucha, 2015. Integrated pest management for sustainable intensification of agriculture in Asia and Africa. Insects, 6: 152-182. DOI: $10.3390 /$ insects6010152

Prihastuti, T., 2014. Commercialization prospects of microbial and Soil microbial formulation in Indonesia in agriculture. Int. J. Soil Crop Sci., 2: 46-53.

Prior, C., 1996. History, use and future of microbial insecticides in urban pest control. Proceeding of the 2nd International Conference on Urban Pests, (CUP' 96), pp: 31-41.

Prokopy, R.J., D.R. Cooley, W.R. Autio and W.M. Coli, 1994. Second-level integrated pest management in commercial apple orchards. Am. J. Alternative Agric., 9: 148-156. DOI: $10.1017 / \mathrm{S} 0889189300005890$ 
Rao, G.V.R, O.P. Rupela, V.R. Rao and Y.V.R. Reddy, 2007. Role of biopesticides in crop protection: Present status and future prospects. Indian J. Plant Protect., 35: 1-9.

Rodgers, P.B., 1993. Potential of biopesticides in agriculture. Pesticide Sci., 39: 117-129.

DOI: $10.1002 / p s .2780390205$

Rongai, D., C. Cerato, L. Lazzeri, S. Palmieri and G. Patalano, 2008. Vegetable oil formulation as biopesticide to control California red scale (Aonidiella aurantii Maskell). J. Pest Sci., 81: 179-185. DOI: $10.1007 /$ s10340-008-0202-4

Rostami, A., K. Hinc, F. Goshadrou, A. Shali and M. Bayat et al., 2017. Display of B. pumilus chitinase on the surface of $B$. subtilis spore as a potential biopesticide. Pesticide Biochem. Physiol., 140: 17-23. DOI: 10.1016/j.pestbp.2017.05.008

Saiyad, S.A., 2017. Application of Bacillus thuringiensis as an effective tool for insect pest control. IOSR J. Agric. Vet. Sci., 10: 27-29.

DOI: $10.9790 / 2380-1007012729$

Scudeler, E.L., A.S.G. Garcia, P.F.F. Pinheiro and D.C. dos Santos, 2017. Neem oil (Azadirachta indica A. Juss) affects the ultrastructure of the midgut muscle of Ceraeochrysa claveri (Navás, 1911) (Neuroptera: Chrysopidae). Acta Histochemica, 119: 84-91.

DOI: 10.1016/j.acthis.2016.11.012

Shapiro-Ilan, D.I., R. Han and X. Qiu, 2014. Production of Entomopathogenic Nematodes. In: Mass Production of Beneficial Organisms: Invertebrates and Entomopathogens, Academic Press, Amsterdam, ISBN-13: 9780123914156, pp: 321-356.

Sharma, S., M. Verma and A. Sharma, 2013. Utilization of non edible oil seed cakes as substrate for growth of Paecilomyces lilacinus and as biopesticide against termites. Waste Biomass Valorizat., 4: 325-330. DOI: 10.1007/s12649-012-9134-6

Shishir, A., A.A. Bhowmik, N.R. Akanda, A. Al Mamun and S.N. Khan et al., 2015. Efficacy of indigenous Bacillus thuringiensis strains for controlling major vegetable pests in Bangladesh. Egypt. J. Biol. Pest Control, 25: 729-734.

Sun, X., 2015. History and current status of development and use of viral insecticides in China. Viruses, 7: 306-319. DOI: 10.3390/v7010306
Szewczyk, B., L. Hoyos-Carvajal, M. Paluszek, I. Skrzecz and M. Lobo De Souza, 2006. Baculoviruses - Re-emerging biopesticides. Biotechnol. Adv., 24: 143-160. DOI: 10.1016/j.biotechadv.2005.09.001

Thakore, Y., 2006. The biopesticide market for global agricultural use. Ind. Biotechnol., 2: 194-208.

DOI: 10.1089/ind.2006.2.194

Thomas, M.B., 1999. Ecological approaches and the development of "truly integrated" pest management. Proc. National Acad. Sci. USA, 96: 5944-5951. DOI: 10.1073/pnas.96.11.5944

Tripathi, Y.N., K. Divyanshu, S. Kumar, L.K. Jaiswal and A. Khan et al., 2020. Biopesticides: Current Status and Future Prospects in India. In: Bioeconomy for Sustainable Development, Keswani, C. (Eds.), Springer, Singapore, ISBN-13: 978-981-13-9431-7, pp: 79-109.

Umar, M.A., 2013. Organic farming in Nigeria: Problems and future prospects. Global Adv. Res. J. Agric. Sci., 2: 256-262.

van Lenteren, J.C., K. Bolckmans, J. Köhl, W.J. Ravensberg and A. Urbaneja, 2017. Biological control using invertebrates and microorganisms: Plenty of new opportunities. Biocontrol, 63: 39-59. DOI: $10.1007 / \mathrm{s} 10526-017-9801-4$.

Villaverde, J.J., P. Sandín-España, B. Sevilla-Morán, C. López-Goti and J.L. Alonso-Prados, 2016. Biopesticides from natural products: Current development, legislative framework and future trends. BioResources, 11: 5618-5640. DOI: 10.15376/biores.11.2.Villaverde

Weselowski, B., N. Nathoo, A.W. Eastman, J. MacDonald and Z.C. Yuan, 2016. Isolation, identification and characterization of Paenibacillus polymyxa CR1 with potentials for biopesticide, biofertilization, biomass degradation and biofuel production. BMC Microbiol., 16: 244-244. DOI: 10.1186/s12866-016-0860-y

Williams, S.D., M.J. Boehm and F. Qu, 2017. Viral diseases of plants. The Ohio State University, College of Food, Agriculture and Environmental Sciences. 